conditions that are associated with a high risk of cardiovascular (CV) complications further beyond the increased prevalence of classical risk factors in this population. Consequently, the early identification of patients with MS-PSO and PsA who may benefit from primary CV prevention is essential. However, medical providers do not routinely screen or counsel their patients for CV risk factors or comorbidities. In addition, paucity of robust clinical data complicates the implementation of management protocols for primary CV prevention in MS-PSO and PsA.

Objectives: To generate expert-based recommendations on the management of CV comorbidities in patients with MS-PSO and PSA through the application of the Delphi technique.

Methods: The development of Delphi-based recommendations included four steps: (1) systematic literature review to explore current information and clinical recommendations on management of $\mathrm{CV}$ comorbidities in patients with $\mathrm{PsO}$ and $\mathrm{PsA}$; (2) two subsequent meetings with project coordinators $(n=3)$ and scientific advisors $(n=7)$ from different medical specialties (rheumatology, dermatology, endocrinology, internal medicine, pneumology, rehabilitation, psychiatry and primary care) to examine the results of the review and decide which statements should be included in the final version of the questionnaire; (3) a two-round Delphi questionnaire aimed at specialists in rheumatology and dermatology to assess the degree of consensus on the different points raised; (4) finally, a face-toface meeting with the project coordinators and scientific advisors to discuss and ratify the results of the Delphi process.

Results: As a result of the literature review and the assessment and approval of scientific advisors, the final version of the Delphi survey contains 52 statements grouped into 35 questions. The questionnaire is divided into 3 topic sections: (1) identification, diagnosis and referral of MSPSO and/or PsA patients with CV comorbidities ( $n=12$ statements); (2) management and treatment of $\mathrm{CV}$ comorbidities associated with MS-PSO and/or PSA ( $n=36)$; (3) influence of MS-PSO and/or PsA treatments on CV comorbidities and vice versa $(n=4)$

Conclusion: This Delphi-based study may fill an important gap in the evidence by providing relevant information on the management of $\mathrm{CV}$ comorbidities in patients with MS-PSO and/or PsA.

Disclosure of Interests: : RAQUEL ALMODOVAR: None declared, Jose Luís López Estebaranz Consultant for: I have received fees as an advisory board member for Pfizer, Novartis, Leo Pharma, Lilly, Celgene, Abbvie and Janssen cilad, Speakers bureau: I have received fees as a speaker for Pfizer, Novartis, Leo Pharma, Lilly, Celgene, Abbvie and Janssen cilad, Eva De Higes Martínez : None declared, María Jesús López Navas : None declared, Carlos Guijarro Herraiz Consultant for: I have received payments as an advisor for Amgen, Esteve, Ferrer, MSD, Pfizer, Rubió and Sanofi., Speakers bureau: I have received payments as a speaker for Amgen, Esteve, Ferrer, MSD, Pfizer, Rubió and Sanofi., Juan José Gorgojo Martínez : None declared, David Palacios : None declared, José Carlos Peláez Álvarez Consultant for: I have received payments for consultancies from Shire Pharmaceuticals lbérica, Pfizer, Merck Sharp Dohme España and Laboratorios Farmaceuticos Rovi., Speakers bureau: I have received lecture fees from Shire Pharmaceuticals Ibérica, Pfizer, Merck Sharp Dohme España and Laboratorios Farmaceuticos Rovi., Diana Ruiz Genao Consultant for: I have received payments for consultancies from Janssen-Cilag,Pfizer, Abbvie, Celgene, Leo Pharma, Novartis, Speakers bureau: I have received lecture fees from Janssen-Cilag,Pfizer, Abbvie, Celgene, Leo Pharma, Novartis., Lucía Pérez Carbonell : None declared, Susana Gómez Employee of: I am a current employee of Pfizer., Erica Falkelbach Employee of: I am a current employee of Pfizer., Francisco Rebollo Employee of: I am a current employee of Pfizer., Pedro Zarco Montejo : None declared

Doi: 10.1136/annrheumdis-2019-eular.6988

\section{FRI0700-HPR LESSONS LEARNED FROM PILOT IMPLEMENTATION OF PHYSICAL ACTIVITY RECOMMENDATIONS IN AXSPA EXERCISE GROUP THERAPY - LESS MAY BE MORE}

Anne-Kathrin Rausch Osthoff ${ }^{1,2}$, Thea Vliet Vlieland ${ }^{2}$, René Braem ${ }^{3}$ Béatrice Walker ${ }^{3}$, Karin Niedermann Schneider ${ }^{1}$. 'Zurich University of Applied Sciences, Institute for Physiotherapy, Health, 8401 Winterthur, Switzerland; ${ }^{2}$ Leiden University Medical Center, Department of Orthopaedics, Rehabilitation and Physical Therapy, Leiden, Netherlands; ${ }^{3}$ Ankylosing Spondylitis Association of Switzerland, Zurich, Switzerland

Background: The Ankylosing Spondylitis Association of Switzerland (SVMB) offers 68 exercise groups (EG) for people with axial Spondyloarthritis (axSpA). Participants exercise weekly with focus on strength and flexibility supervised by a physiotherapist (PT). Given the EULAR physical activity (PA) recommendations [1] and recent research [2, 3], the SVMB aims to further develop the concept of their EG by introducing: a) exercises in all dimensions, cardiorespiratory fitness, muscle strength, flexibility and neuromotor performance, according to the general PA recommendations [4]; b) individual exercise-coaching (three sessions in first six months) by the group PT, specifically trained in communication and action planning skills to support individual exercising, and c) bi-annual fitness-assessments for all exercise dimensions.

Objectives: To evaluate the new EG concept among the participating people with axSpA and PTs across four pilot groups.

Methods: After six months, a survey on the perception and satisfaction towards the new EG concept was sent to 30 people with axSpA, who rated the questions on a $0-10$ numeric rating scale $(0=$ not satisfied, $10=$ very satisfied). Semi-structured telephone-interviews were conducted with the PTs to explore their experiences with the new GE concept.

Results:

People with axSpA: The survey's response rate was $83 \%(25 / 30)$; of these, $15(62 \%)$ participants were satisfied with the concept (mean 6.7

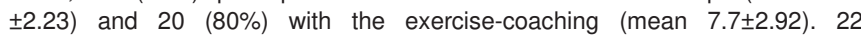
$(88 \%)$ individuals defined a training goal and $15(60 \%)$ achieved it. The exercise diary was used by 16 (64\%) participants, five reported appbased. Reasons for not using the diary were the daily effort and problems with correctly allocating activities to exercise dimensions. A minority $(n=7,28 \%)$ reported to use a technical device for cardiovascular exercising. $17(68 \%)$ were satisfied with the fitness-assessment (mean 7.5 \pm 1.78 ) PTs perceived the exercise-coaching as very useful for supporting individ ualised exercising. However, they emphasised that the frequency of the sessions should be flexibly based on the participant's individual training goal and motivation. The PTs perceived controversial reactions to the fit ness-assessments: increased but also decreased motivation towards exercising.

Conclusion: Exercise-coaching and fitness-assessments were generally appreciated; however, the frequency was perceived as too high. The GE concept will be adapted accordingly to improve feasibility for national implementation: the exercise-coachings will be reduced to two in the first six months, the first one compulsory for all participants, then bi-annually, according to individual needs and training goals. The fitness-assessments will take place annually instead of bi-annually. There is a need for easyto-use exercise diaries, covering all exercise dimensions.

\section{REFERENCES:}

[1] Rausch AK, et al. Ann Rheum Dis 2018; 9(77):1251-1260.

[2] Sveaas SH, et al. Br J Sports Med 2017;51:1065-1072

[3] Rausch AK, et al. RMD open, accepted

[4] Garber CE, et al. Med Sci Sports Exerc 2011;43:1334-59.

Disclosure of Interests: None declared

DOI: 10.1136/annrheumdis-2019-eular.7188

\section{FRI0701-HPR EFFICACY OF INTERMITTENT AEROBIC EXERCISE ON SLEEP EFFICIENCY IN PATIENTS WITH RHEUMATOID ARTHRITIS. A RANDOMIZED CONTROLLED TRIAL}

Katrine Løppenthin ${ }^{1}$, Julie Midtgaard ${ }^{2,3}$, Bente Appel Esbensen ${ }^{1,4}$

Mikkel Ǿstergaard ${ }^{1,4}$, Jesper Frank Christensen ${ }^{5}$, Tanja Thomsen ${ }^{1}$,

Anders Tolver ${ }^{6}$, Poul Jennum ${ }^{4,7} .{ }^{1}$ Rigshospitalet, Copenhagen Center for Arthritis Research (COPECARE), Center for Rheumatology and Spine Diseases, Centre of Head and Orthopaedics, Glostrup, Denmark; ${ }^{2}$ Rigshospitalet, University Hospitals Centre for Health Care Research (UCSF), Copenhagen University Hospital,

Copenhagen, Denmark; ${ }^{3}$ University of Copenhagen, Department of Public Health, Faculty of Health and Medical Sciences, Copenhagen, Denmark; ${ }^{4}$ University of Copenhagen, Department of Clinical Medicine, Copenhagen, Denmark;

${ }^{5}$ Rigshospitalet, Copenhagen, Centre for Inflammation and Metabolism/Centre for Physical Activity Research, Copenhagen, Denmark; ${ }^{6}$ University of Copenhagen, Department of Mathematical Sciences Faculty of Science, Copenhagen, Denmark; ${ }^{7}$ Rigshospitalet, Danish Center for Sleep Medicine, Department of Clinical Neurophysiology, Glostrup, Denmark

Background: Insomnia is seen in $>60 \%$ of patients with rheumatoid arthritis (RA). While cross-sectional studies have shown a positive association between regular physical activity and good sleep, there is a lack of knowledge on the effect of physical activity on insomnia in patients with RA.

Objectives: To examine the efficacy of intermittent aerobic exercise on sleep efficiency as well as the effect on fatigue and depressive symptoms 
Methods: 38 patients with RA were randomly assigned to either intermittent aerobic exercise training; 3 session/week for 6 weeks; intervention group $(n=17)$ or usual care (controls group $n=21$ ). The primary outcome was change in polysomnography (PSG) assessed sleep efficiency while secondary outcomes included sleep (Pittsburgh Sleep Quality Index), fatigue (Bristol Rheumatoid Arthritis Fatigue Multi-Dimensional Questionnaire) and depression (The Center for Epidemiological StudiesDepression).

Results: Sleep efficiency improved significantly in the intervention group from baseline $0.84(95 \% \mathrm{Cl} 0.80-0.87)$ to end of the intervention 0.88 (95\% Cl $0.84-0.92) \quad p=0.03$, while for the control group the mean change was not significant. No between-group difference in change was observed. Fatigue was significantly reduced in the intervention group compared to the control group $-16.0(95 \% \mathrm{Cl}-25.1-7,04)$, including physical fatigue $-4.99(95 \% \mathrm{Cl}-7.25--2.74)$, cognitive fatigue $-2.43(95 \% \mathrm{Cl}-4.22-$ $-0.63)$ and living with fatigue $-2.50(95 \% \mathrm{Cl}-4.45--0.54)$.

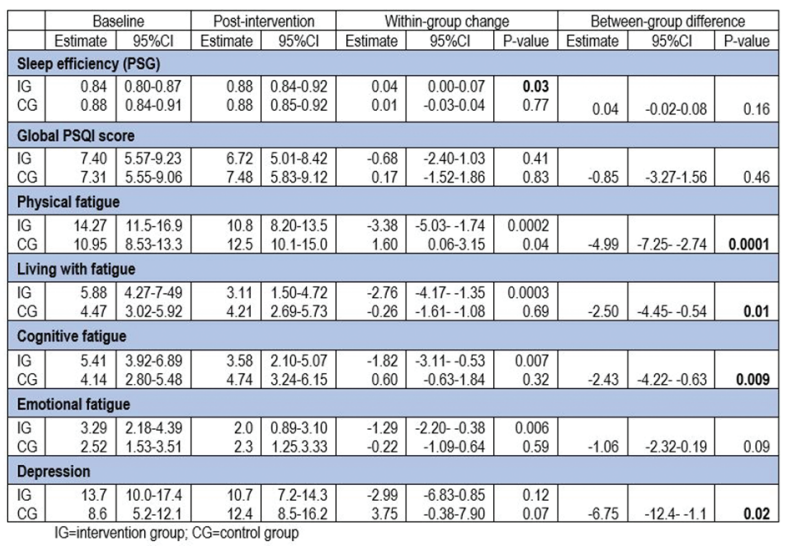

Conclusion: An intermittent aerobic exercise intervention presented no statistically significant effect on sleep efficiency in patients with RA compared with usual care. However, significant between-group differences were seen in subjectively reported fatigue including physical fatigue and cognitive fatigue and on depressive symptoms.

\section{REFERENCES:}

[1] Loppenthin K, Esbensen BA, Jennum P, et al. Effect of intermittent aerobic exercise on sleep quality and sleep disturbances in patients with rheumatoid arthritis - design of a randomized controlled trial. BMC musculoskeletal disorders 2014

Disclosure of Interests: Katrine Løppenthin: None declared, Julie Midtgaard: None declared, Bente Appel Esbensen Speakers bureau: For Pfizer, Mikkel Ǿstergaard Grant/research support from: Abbvie, Celgene, Centocor, Merck, Novartis, Consultant for: Abbvie, BMS, Boehringer-Ingelheim, Celgene, Eli Lilly, Hospira, Janssen, Merck, Novartis, Novo, Orion, Pfizer, Regeneron, Roche, and UCB, Speakers bureau: Abbvie, BMS, Boehringer-Ingelheim, Celgene, Eli Lilly, Hospira, Janssen, Merck, Novartis, Novo, Orion, Pfizer, Regeneron, Roche, and UCB, Jesper Frank Christensen: None declared, Tanja Thomsen: None declared, Anders Tolver: None declared, Poul Jennum: None declared

DOI: 10.1136/annrheumdis-2019-eular.2809

\section{FRI0702-HPR NON PHARMACOLOGICAL MANAGEMENT OF FIBROMYALGIA: A SYSTEMATIC REVIEW OF SYSTEMATIC REVIEWS}

Pamela Andrews, Lorna Paul, Martijn Steultjens. Glasgow Caledonian University, School of Health and Life Sciences, Glasgow, United Kingdom

Background: Despite the number of guidelines and available therapies, many individuals with fibromyalgia (FM) still experience significant pain and a reduced quality of life. Patient heterogeneity and clinical uncertainty can lead to delays in selecting the most appropriate management strategy. There are more than 300,000 publications surrounding the management of FM, thus affecting clinicians' ability to make informed decisions. The systematic review of randomised controlled trials is the gold standard in evaluating an intervention. However, the increase in systematic reviews
(SRs) has led to some questions regarding their quality. Therefore there is a need to synthesise the evidence with an overview of SRs.

Objectives: To evaluate the quality of the current evidence from SRs on the effects of non-pharmacological interventions for the management of FM.

Methods: A systematic search of seven databases (1990-2018) was completed to identify SRs reporting the effects of non-pharmacological interventions on the primary outcomes of pain, function and quality of life (QoL). Data was extracted according to the PICO framework in addition to intervention prescription where appropriate. Methodological quality was assessed using the Assessing the Methodological Quality of Systematic Reviews (AMSTAR-2) instrument (Shea et al 2017).

Results: Twenty-six SRs with 243 primary studies met the inclusion criteria. Reviews were classified into 6 categories (1) land-based exercise; (2) water-based exercise; (3) mind-body; (4) electrotherapy; (5) manual therapy and (6) complementary and alternative medicine (CAM). Quality of the included SRs were variable with many interventions scoring low to critically low. High quality evidence was found to support the use of land-based exercise and mind-body therapies for the improvement of pain, function and QoL (Table). In particular aerobic exercise with or without strength training and mind-body therapies demonstrated the best outcome.

Conclusion: With the exception of land-based exercise and mind-body exercise, the quality of evidence for the non-pharmacological management of FM is mostly poor, with more than half of the included reviews scoring low or critically low on the AMSTAR-2 instrument. Improved reporting of outcome data and stricter methodological quality will allow stronger recommendations in the future.

\section{REFERENCES}

[1] Shea, B.J., et al., AMSTAR 2: a critical appraisal tool for systematic reviews that include randomised or non-randomised studies of healthcare interventions, or both. bmj, 2017. 358: p. j4008 0959-8138.

Table: Quality of reviews surrounding interventions on FM

\begin{tabular}{lcc}
\hline & Results $^{*}$ & Quality of evidence \\
\hline Land-based exercise (3) & $\mathrm{Pain}^{+} /$function $^{+} / \mathrm{QoL}^{+}$ & High \\
Water-based exercise (5) & $\mathrm{Pain}^{+} / \mathrm{function}^{+}$ & Moderate \\
Mind-body therapies (4) & $\mathrm{Pain}^{+} / \mathrm{QoL}^{+}$ & High \\
Electrotherapies (8) & $\mathrm{Pain}^{+} / \mathrm{QoL}^{+}$ & Low \\
Manual therapy (3) & $\mathrm{Pain}^{+}$ & Critically Low \\
CAM (3) & $\mathrm{Pain}^{+}$ & Low \\
\hline
\end{tabular}

${ }^{*}+=$ positive effects, ? = no or unclear results

Disclosure of Interests: None declared DOI: 10.1136/annrheumdis-2019-eular.5419

\section{FRI0703-HPR INVESTIGATION OF THE EFFECTIVENESS OF AEROBIC EXERCISE TRAINING IN INDIVIDUALS WITH ANKYLOSING SPONDYLITIS: RANDOMIZED CONTROLLED STUDY}

Bilge Basakci Calik ${ }^{1}$, Mine Pekesen Kurtca ${ }^{2}$, Elif Gur Kabul ${ }^{1}$, Orcin Telli Atalay ${ }^{1}$, Harun Taskın ${ }^{1}$, Murat Yigitt ${ }^{3}$, Murat Tascl ${ }^{3}$, Veli Cobankara ${ }^{3} .{ }^{1}$ Pamukkale University, School Of Physical Therapy and Rehabilitation, Denizli, Turkey, ${ }^{2}$ Pamukkale University, Denizli, Turkey; ${ }^{3}$ Pamukkale University, Department of Rheumatology, Denizli, Turkey

Background: Aerobic capacity is a measure of the functional capacity of the oxygen system and the cardiopulmonary system. In Ankylosing spondylitis(AS) patients, aerobic capacity is lower than healthy peers, and this is due to inflammation, muscle atrophy and peripheral muscle weakness fatigue, low physical activity level, negatively affected respiratory function, peripheral arthritis, decreasing chest expansion and respiratory muscle strength.

Objectives: The aim of the study was to investigate the effects of aerobic exercise training on functional status and aerobic capacity in individu als with AS.

Methods: Twenty-eight voluntary individuals diagnosed with AS according to Modifie New York Criteria who applied to Pamukkale University Department of Internal Medicine, Department of Rheumatology were included in the study. Individuals were randomly divided into two groups, as there would be aerobic exercise training $(n=17$; mean age $=46.58$ \pm 11.94 years $)$ and supervised exercises group $(n=11$; mean age $=42.54$ \pm 8.75 years). All assessments were done before and after the training. 